\title{
ẢNH HƯởNG CỦA VỊ TRí ĐƯờNG HOÀN TẤT LÊN CHỈ SỐ NHA CHU LÂM SÀNG CỦA MÃO TOÀN SỨ VÙNG RĂNG TRƯớC
}

\author{
Phạm Thị Kiều Loan*, Đoàn Minh Trí*, Nguyễn Ngọc Yến Thư*
}

\section{TÓM TẮT}

Mục tiêu: Đánh giá ảnh hưởng của vị trí đường hoàn tất (ĐHT) lên tình trạng lâm sàng mô nha chu của mão răng toàn sứ. Đối tượng và phương pháp: Nghiên cứu trên 20 răng trước đã nội nha từ 17 bệnh nhân có nhu cầu thưc hiên mão toàn sứ tai khu điều trị 3, Bộ môn Phục hình, Khoa Răng Hàm Mặt, Đại học Y Dược TP. Hồ Chí Minh. Các đối tượng được chia thành 2 nhóm: 10 răng được sửa soạn với ĐHT ngang nướu (nhóm N), 10 răng được sửa soạn với ĐHT dưới nướu (nhóm D), nhóm chứng là các răng thật lành mạnh đối bên mão răng. Các chỉ sốnha chu lậm sàng được ghi nhận tại 3 thời điểm: ngày 1 , ngày 45 và ngày 90 sau khi gắn mão. Kết quả: Các chỉ số nha chu lâm sàngcủa mão răng toàn sứ có ĐHT ngangvà dưới nướu tại các thời điểm nghiên cứukhông có sư khác biệt có ý nghĩa thống kê so với nhóm chứng. Ngoài ra, cũng không có sự khác biệt có ý nghĩa thống kể khi so sánh các chỉ số này giữa 2 nhóm mão. Kêt luận: Vị trí ĐHT (ngang và dưới nướu) khôngảnh hưởng đến các chỉ số nha chu lâm sàng khi thực hiện mão toàn sứ vùng răng trước.

Tư khoá: Mão toàn sứ, ĐHT ngang nướu, ĐHT dưới nướu, chỉ số nha chu lâm sàng.

\section{SUMMARY}

THE INFLUENCE OF FINISHLINE POSITIONS ON THE PERIODONTAL CLINICAL PARAMETERS OF ANTERIOR ALL-CERAMIC CROWNS

Objectives: The influence of the positions of the finish lines on the clinical status of periodontal softtissueofall-ceramic crowns was evaluated. Method: Studying from 20 endodontically treated teeth in the maxillary anterior zone of 17 patients who performed all-ceramic crowns at the Dental Clinic 3, Prosthodontics Department, Faculty of OdontoStomatology, University of Medicine and Pharmacy, Ho Chi Minh City. The subjects were divided into 2 groups, includingof 10 teeth (group N withgingivalfinish lines) and 10 teeth remain (group D - with subgingival finish lines). The control teeth were the contralateral healing teeth. Theperiodontal parameters were recorded at 3 time points: day 1, day 45 and day 90 after permanent fixed crowns. Results: The periodontal clinical parameters of allceramic crowns with gingival and subgingival finish line groups inthe studywere no statistically significant differences incomparing with the control tooth group.

*Đai hoc Y Dướ TP. Hồ Chí Minh

Chịu trách nhiệm chính: Phạm Thị Kiều Loan

Email: kieuloanpham1804@gmail.com

Ngày nhận bài: 5/9/2021

Ngày phản biên khoa hoc: 5/10/2021

Ngày duyệt bài: 20/10/2021
In addition, there was no statistically significant difference in comparingthe periodontal parameters between two groups of ceramic crowns. Conclusion: The positions of finish lines (gingival and subgingival finish lines) do not affect the periodontal clinical parameters when all-ceramic crowns were done in the anterior teeth.

Keywords: all-ceramic crowns, gingival finish line, subgingival finish line,periodontal clinical parameters.

\section{I. ĐĂT VẤN ĐỀ}

Hình dạng và vị trí đường hoàn tất (ĐHT) là những yếu tố quan trongkhi sửa soạn cùi răngvà có ảnh hưởng đến tình trạng lành mạnh của mô nha chudo đó cần được quan tâm đặc biệt. Phục hình với ĐHT trên nướu giúp bệnh nhân dễ vệ sinh tuy nhiên gây bất lợi về mặt thẩm mỹ nhất là vùng răng trước, trong khi đó ĐHT dưới nướu tuy thẩm mỹ nhưng có thể gây ảnh hưởng cho sự lành manh củamô nướu, ĐHT ngang nướu được xem là kết hợp ưu nhược điểm của 2 loại trên [3],[8]. Việc lựa chọn vị trí ĐHT cho phục hình là vấn đề gây băn khoăn trong thực hành lâm sàng.

Vât liệu sứ ra đời, đáp ứng tốt về măt thẩm mỹ và có tính tương hợp sinh hoc cao nhưng vẫn còn tồn tại một số câu hỏi mở liên quan đến khả năng tương thích của chúng với mô nha chu trong môi trường miệng [1].

Từ lâu, việc chẩn đoán viêm nướu và viêm nha chu dựa trên đánh giá các chỉ số lâm sàng như chỉ số mảng bám (PI), chỉ số nướu (GI), độ sâu thăm dò $(P D)$, mất bám dính (CAL),.... Những chỉ số này là tiêu chuẩn lâm sàng được sử dụng trong nghiên cứu, có giá trị đối với việc chẩn đoán và điều trị trong phục hồi nha khoa.

Nghiên cứu được tiến hành nhằm đánh giá ảnh hưởng của các vị trí đường hoàn tất khác nhau tác động lên sự lành mạnh của mô nha chu sau khi thực hiện mã̃o toàn sứ ở răng trước hàm trên đã nội nha vào 3 thời điểm: ngày 1 , ngày 45 và ngày 90 sau khi gắn mão.

\section{II. ĐỐI TƯỢNG VÀ PHƯƠNG PHÁP NGHIÊN CỨU}

2.1. Đối tượng nghiên cứu. 20 răng phía trước hàm trên đã điêuu trị nội nha từ 17 bênh nhân có mong muốn thực hiên phục hồi cố định mão răngtoàn sứ tại khu điều trị Bộ môn Phục hình, Khoa Răng Hàm Mắt, Đại học $Y$ Dược TP Hồ Chí Minh từ tháng 9 năm 2020 đến tháng 7 năm 2021. 
Các răng nghiên cứu được chia ngẫu nhiên vào 2 nhóm:

- Nhóm N: 10 răng được thực hiện mão toàn sứ với ĐHT ngang nướu

- Nhóm D: 10 răng được thực hiện mão toàn sứ với ĐHT dưới nướu $0.5 \mathrm{~mm}$

Răng thật có mô nướu lành mạnh không có phục hình ở vị trí đối bên cùng tên (nếu không còn răng cùng tên đối bên thì chọn răng ở vị trí gần đó) được chọn vào nhóm chứng.

2.1.1. Tiêu chuẩn chọn mẫu

- Bênh nhân từ 18 tuổi trở lên.

- Răng vùng phía trước hàm trên (răng cửa, răng nanh, răng cối nhỏ), không có triệu chứng lâmsàng, đã điêu trị nội nha tốt, không có dâu hiệu tiêu xương hay viêm quanh chóp trên phim tia Xvà có chỉ định phục hồi cố định mão răng.

- Bệnh nhân đồng ý tham gia nghiên cứu.

\subsubsection{Tiêu chuẩn loai trừ} động.

- Bệnh nhân có bệnh viêm nha chu đang hoạt

- Bệnh nhân được điều trị phẫu thuật nha chu $\leq 6$ tháng trên răng nghiên cứu.

- Răng nghiên cứu có độ sâu thăm dò $<1 \mathrm{~mm}$ hoặc $>3 \mathrm{~mm}$, chiều cao nướu dính $<2 \mathrm{~mm}$, hoặc chiều cao thân răng thấp $(<3 \mathrm{~mm})$.

- Bệnh nhân có bệnh toàn thân (cao huyết áp, nội tiết, thận, huyết học, gan, ức chế miễn dịch) hoặc đang dùng thuốc kháng sinh/kháng viêm. con bú

- Bệnh nhân đang mang thai hoặc cho đang

- Bệnh nhân không có muốn tham gia nghiên cứu hoặc không quay lại tái khám.

\subsection{Phương pháp nghiên cứu}

2.2.1. Thiết kế nghiên cứu: Nghiên cứu thử nghiệm lâm sàng ngẫu nhiên, có đối chứng.

2.2.2. Phương tiện nghiên cứu:

- Bộ đồ khám, cây đo túi UNC-15. khoan.

- Dụng cụ sửa soạn răng: tay khoan, bộ mũi

- Vật liệu lấy dấu Polyvinyl siloxane.

- Mão toàn sứ zirconia.

- Xi măng gắn tạm không Eugenol, xi măng gắn vĩnh viễn glass ionomer (GC Fuji 1).

\subsection{Tiến trình nghiên cứu:}

Bước 1. Khám và thu thập thông tin ban đâu

\section{KẾT QUẢ NGHIÊN CỨU}

3.1. Đặc điểm mẫu nghiên cứu

Bảng 1. Đặc điểm mẩu nghiên cứu
- Khám lâm sàng, hỏi bệnh sử và lập phiếu khám. - Chụp phim X-quang răng thực hiện phục hình.

- Lấy dấu sơ khởi, làm răng tạm.

\section{Bước 2. Thực hiện mão toàn sứ}

- Sửa soạn cùi răng cho mão toàn sứ với ĐHT bờ cong dày $1 \mathrm{~m}$; nhóm $\mathrm{N}$ : mài $\mathrm{ÐHT}$ ngang nướu; nhóm D: mài ĐHT ngang nướu, sau đó đặt chỉ co nướu và hạ thấp ĐHT mặt ngoài thêm $0.5 \mathrm{~mm}$.

- Đặt chỉ co nướu và lấy dấu bằng cao su Polyvinyl Siloxane.

- Gắn phục hình tạm.

- Chuyểndấu cao su cho labo thực hiện mão toàn sứ zirconia.

\section{Bước 3. Thử mão và gắn mão}

- Thử và điều chỉnh mão răng.

- Gắn phục hình vĩnh viễn bằng xi măng Fuji 1 và làm sạch xi măng dư.

Quá trình thực hiện, gắn phục hình được kiểm soát bởi giảng viên Bộ môn Phục hình và đảm bảo độ khít sát của mão răng cũng như lượng cement dư được lấy sạch hoàn toàn.

Bước 4. Đánh giá các chỉ số nha chu lâm sàng: Vào 3 thời điểm sau khi gắn mão răng: ngày $1\left(T_{0}\right)$, ngày $45\left(T_{1}\right)$ và ngày $90\left(T_{2}\right)$

Ghi nhận các chỉ số đánh giá lâm sàng nha chu ở vị trí mặt ngoài của răng thực hiện nghiên cứu và răng đối chứng, gồm độ sâu thăm dò $(\mathrm{PD})$, chỉ số mảng bám (PI) theo Löe và Silness (1964)[7], chỉ số nướu (GI) theo Löe và Silness (1963)[2].

2.4. Phương pháp xử lý và phân tích số liệu. Các thông tin và số liệu được ghi nhận vào phiếu thu thập thông tin, sau đó nhập vào phần mềm Excel 2019, phân tích và xử lý dữ liệu bằng phần mềm thống kê SPSS 20.

Tất cả các phân tích được tiến hành với độ tin cậy $95 \%$.

2.5. Đạo đức nghiên cứu. Bệnh nhân có quyền tự nguyện tham gia nghiên cứu và có thể rút khỏi nghiên cứu bất kỳ lúc nào trong suốt quá trình nghiên cứu. Bệnh nhân được cung cấp đây đủ thông tin về quá trình nghiên cứu trước khi tham gia nghiên cứu. Các thông tin cá nhân của bệnh nhân được bảo mật, chỉ phục vụ cho mục đích nghiên cứu.

\begin{tabular}{|c|c|c|c|c|}
\hline & Răng cửa giữa & Răng cửa bên & Răng cối nhỏ & Tổng số \\
\hline Nhóm N & 6 & 2 & 2 & $\mathrm{~N}=10$ \\
\hline Nhóm D & 6 & 2 & 2 & $\mathrm{~N}=10$ \\
\hline Tỉ lệ & $60 \%$ & $20 \%$ & $20 \%$ & $100 \%$ \\
\hline
\end{tabular}


Nghiên cứu thực hiện trên 20 răng nghiên cứu $(R N)$ và 20 răng chứng $(R C)$ từ 17 bệnh nhân có độ tuổi từ 18 - 49 tuổi. Các răng nghiên cứu được chia đều vào 2 nhóm mão răng có đường hoàn tất ngang nướu (nhóm N) và dưới nướu (nhóm $\mathrm{D}$ ), mỗi nhóm gồm 10 răng.

\subsection{Các chỉ số nha chu lâm sàng củanhóm $\mathbf{N}$ và nhóm răng chứng}

Bảng 2. Các chỉ số nha chu lâm sàng của nhóm N và nhóm chứng tại 3 thời điểm

\begin{tabular}{|c|c|c|c|c|c|c|c|c|c|}
\hline \multirow[b]{2}{*}{$\begin{array}{l}\text { Thời } \\
\text { điểm }\end{array}$} & \multicolumn{2}{|c|}{ PI } & \multirow[b]{2}{*}{$\mathrm{P}_{\mathrm{PI}}{ }^{(\mathrm{mw})}$} & \multicolumn{2}{|c|}{ GI } & \multirow[b]{2}{*}{$\mathrm{P}_{\mathrm{GI}}{ }^{(\mathrm{mw})}$} & \multicolumn{2}{|c|}{ PD } & \multirow[b]{2}{*}{$\operatorname{PPD}^{(t)}$} \\
\hline & $\begin{array}{c}\text { Nhóm } \\
\mathbf{N}\end{array}$ & $\begin{array}{l}\text { Nhóm } \\
\text { chứng } \mathbf{N}\end{array}$ & & $\begin{array}{c}\text { Nhóm } \\
\text { N }\end{array}$ & $\begin{array}{l}\text { Nhóm } \\
\text { chứng N }\end{array}$ & & $\begin{array}{c}\text { Nhóm } \\
\mathbf{N}\end{array}$ & $\begin{array}{c}\text { Nhóm } \\
\text { chứng N }\end{array}$ & \\
\hline To & $\begin{array}{c}0.23 \pm \\
0,16\end{array}$ & $0.3 \pm 0.19$ & $p>0.05$ & $\begin{array}{c}0.3 \pm \\
0.19\end{array}$ & $\begin{array}{c}0.23 \pm \\
0.16\end{array}$ & $p>0.05$ & $\begin{array}{c}1.37 \pm \\
0.37\end{array}$ & $1.47 \pm 0.32$ & $p>0.05$ \\
\hline $\mathbf{T}_{1}$ & $0.3 \pm 0.1$ & $\begin{array}{c}0.47 \pm \\
0.32 \\
\end{array}$ & $p>0.05$ & $\begin{array}{c}0.36 \pm \\
0.25 \\
\end{array}$ & $\begin{array}{c}0.33 \pm \\
0.27\end{array}$ & $p>0.05$ & $\begin{array}{c}1.37 \pm \\
0.37 \\
\end{array}$ & $1.47 \pm 0.32$ & $p>0.05$ \\
\hline $\mathbf{T}_{2}$ & $\begin{array}{c}0.33 \pm \\
0.22\end{array}$ & $\begin{array}{c}0.53 \pm \\
0.24\end{array}$ & $p>0.05$ & $\begin{array}{c}0.43 \pm \\
0.28\end{array}$ & $\begin{array}{c}0.36 \pm \\
0.25\end{array}$ & $p>0.05$ & $\begin{array}{c}1.37 \pm \\
0.37\end{array}$ & $1.47 \pm 0.32$ & $p>0.05$ \\
\hline PT0-T1 & $p>0.05$ & $p>0.05$ & & $p>0.05$ & $p>0.05$ & & - & - & \\
\hline$P_{\text {T1-T2 }}$ & $p>0.05$ & $p>0.05$ & & $p>0.05$ & $p>0.05$ & & - & - & \\
\hline Pт0-т2 & $p>0.05$ & $0.026 *$ & & $p>0.05$ & $p>0.05$ & & - & - & \\
\hline & \multicolumn{2}{|c|}{ Kiếm đinh Wilcoxon } & & \multicolumn{2}{|c|}{ Kiếm đinh Wilcoxon } & & & & \\
\hline
\end{tabular}

(mw) Kiếm định Mann-Whitney; ${ }^{(\mathrm{t})}$ Kiếm định $\mathrm{t}$ - test độc lập

Giá trị PI của nhóm $\mathrm{N}$ thấp hơn so với nhóm chứng ở cả 3 thời điểm ngày 1 , ngày 45 và ngày 90 sau khi gắn mão, sự khác biệt không có ý nghĩa thống kê $(p>0.05)$. Ngoài ra, nhóm $\mathrm{N}$ có PI tăng theo thời gian (ngày 1 là $0.23 \pm 0,16$ đến ngày 90 là $0.33 \pm 0.22$ ), nhưng sự khác biệt cũng không có ý nghĩa thống kê giữa các thời điểm $(p>0.05)$.

Giá trị GI của nhóm $\mathrm{N}$ cao hơn so với nhóm chứng ở cả 3 thời điểm, nhưng sự khác biệt này

không có ý nghĩa thống kê ( $p>0.05)$. Mặt khác, nhóm $\mathrm{N}$ có $\mathrm{GI}$ tăng theo thời gian (ngày 1 là 0.3 \pm 0.19 đến ngày 90 là $0.43 \pm 0.28$ ), nhưng sự khác biệt cũng không có ý nghĩa thống kê giữa các thời điểm $(p>0.05)$.

Giá trị PD của nhóm N không có sự khác biệt có ý nghĩa thống kê so với nhóm chứng ở cả 3 thời điểm đánh giá $(p>0.05)$. Ngoài ra, $P D$ không thay đổi theo thời gian ở cả nhóm $\mathrm{N}$ và nhóm chứng.

\subsection{Các chỉ số nha chu lâm sàng của nhóm $D$ và nhóm răng chứng}

Bàng 3. Các chỉ số nha chu lâm sàng của nhóm D và nhóm chứng tại ba thời điểm

\begin{tabular}{|c|c|c|c|c|c|c|c|c|c|}
\hline \multirow[b]{2}{*}{$\begin{array}{l}\text { Thời } \\
\text { điểm }\end{array}$} & \multicolumn{2}{|r|}{ PI } & \multirow[b]{2}{*}{$\mathrm{P}_{\mathrm{PI}}{ }^{(\mathrm{mw})}$} & \multicolumn{2}{|c|}{ GI } & \multirow[b]{2}{*}{$\mathbf{P}_{\mathrm{GI}}{ }^{(\mathrm{mw})}$} & \multicolumn{2}{|c|}{ PD } & \multirow[b]{2}{*}{$\mathrm{P}_{\mathrm{PD}}{ }^{(t)}$} \\
\hline & $\begin{array}{c}\text { Nhóm } \\
\text { D }\end{array}$ & $\begin{array}{l}\text { Nhóm } \\
\text { chứng D }\end{array}$ & & $\begin{array}{c}\text { Nhóm } \\
\text { D }\end{array}$ & $\begin{array}{l}\text { Nhóm } \\
\text { chứng D }\end{array}$ & & $\begin{array}{c}\text { Nhóm } \\
\text { D }\end{array}$ & $\begin{array}{c}\text { Nhóm } \\
\text { chứng D }\end{array}$ & \\
\hline To & $\begin{array}{c}0.26 \pm \\
0.14\end{array}$ & $0.33 \pm 0.22$ & $p>0.05$ & $\begin{array}{c}0.33 \pm \\
0.16\end{array}$ & $0.3 \pm 0.1$ & $p>0.05$ & $\begin{array}{c}1.45 \pm \\
0.29\end{array}$ & $\begin{array}{c}1.4 \pm \\
0.25\end{array}$ & $p>0.05$ \\
\hline $\mathbf{T}_{1}$ & $\begin{array}{c}0.33 \pm \\
0.16\end{array}$ & $0.5 \pm 0.33$ & $p>0.05$ & $\begin{array}{c}0.47 \pm \\
0.18\end{array}$ & $0.37 \pm 0.19$ & $p>0.05$ & $\begin{array}{c}1.45 \pm \\
0.29\end{array}$ & $\begin{array}{c}1.4 \pm \\
0.25\end{array}$ & $p>0.05$ \\
\hline $\mathbf{T}_{2}$ & $\begin{array}{c}0.36 \pm \\
0.11\end{array}$ & $0.57 \pm 0.23$ & $p>0.05$ & $0.5 \pm 0.24$ & 0.14 & $p>0.05$ & $\begin{array}{c}1.43 \pm \\
0.27\end{array}$ & $\begin{array}{l}1.4 \pm \\
0.25\end{array}$ & $p>0.05$ \\
\hline Pт0-т1 & $p>0.05$ & $p>0.05$ & & $p>0.05$ & $p>0.05$ & & - & - & \\
\hline P $_{\text {T1-T2 }}$ & $p>0.05$ & $p>0.05$ & & $p>0.05$ & $p>0.05$ & & $p>0.05$ & - & \\
\hline Pт0-т2 & $p>0.05$ & $p>0.05$ & & $p>0.05$ & $p>0.05$ & & $p>0.05$ & - & \\
\hline & \multicolumn{2}{|c|}{ Kiểm định Wilcoxon } & & \multicolumn{2}{|c|}{ Kiểm định Wilcoxon } & \multicolumn{3}{|c|}{$\begin{array}{c}\text { Kiếm định t-test băt } \\
\text { cặp }\end{array}$} & \\
\hline
\end{tabular}

${ }^{(\mathrm{mw}) K i e ̂ ̉ m ~ đ i ̣ n h ~ M a n n-W h i t n e y ; ~}{ }^{(\mathrm{t})}$ Kiếm định $\mathrm{t}$ - test độc lập

Giá trị PI của nhóm $D$ thấp hơn so với nhóm chứng ở cả 3 thời điểm ngày 1 , ngày 45 và ngày 90 sau khi gắn mão, sự khác biệt này không có ý nghĩa thống kê $(p>0.05)$. Ngoài ra, nhóm $D$ có PI tăng theo thời gian (ngày 1 là $0.26 \pm 0.14$ đến ngày 90 là $0.36 \pm 0.11)$, nhưng sự khác biệt cũng không có ý nghĩa thống kê giữa các thời điểm $(p>0.05)$.
Giá trị GI của nhóm $D$ cao hơn so với nhóm chứng ở cả 3 thời điểm, sự khác biệt này không có ý nghĩa thống kê ( $p>0.05)$. Mặt khác, nhóm $\mathrm{D}$ có $\mathrm{GI}$ tăng theo thời gian (ngày 1 là $0.33 \pm$ 0.16 đến ngày 90 là $0.5 \pm 0.24$ ), nhưng sự khác biệt không có ý nghĩa thống kê giữa các thời điểm $(p>0.05)$.

Giá trị PD của nhóm D không có sự khác biệt 
có ý nghĩa thống kê so với nhóm chứng ở cả 3 thời điểm đánh giá $(p>0.05)$. Nhóm $D$ có PD ở ngày 1 là $1.45 \pm 0.29$ sau đó giảm xuống $1.43 \pm$
0.27 ở ngày 90, nhưng sự khác biệt này không có ý nghĩa thống kê ( $p>0.05)$.

\subsection{So sánh các chỉ số nha chu lâm sàng của nhóm $\mathbf{N}$ và nhóm $\mathrm{D}$}

Bảng 4. So sánh các chỉ số nha chu lâm sàng giữa 2 nhóm $N$ và $D$

\begin{tabular}{|c|c|c|c|c|c|c|c|c|c|}
\hline \multirow{3}{*}{$\begin{array}{l}\text { Thời } \\
\text { điểm }\end{array}$} & \multirow{2}{*}{\multicolumn{2}{|c|}{ PI }} & \multirow{3}{*}{$\mathrm{p}_{\mathrm{PI}}(\mathrm{mw})$} & \multirow{2}{*}{\multicolumn{2}{|c|}{ GI }} & \multirow{3}{*}{$\mathrm{P}_{\mathrm{GI}}{ }^{(\mathrm{mw})}$} & \multirow{2}{*}{\multicolumn{2}{|c|}{ PD }} & \multirow[b]{3}{*}{$\operatorname{PPD}^{(t)}$} \\
\hline & & & & & & & & & \\
\hline & $\begin{array}{c}\text { Nhóm } \\
\mathbf{N}\end{array}$ & $\begin{array}{c}\text { Nhóm } \\
\text { D }\end{array}$ & & $\underset{\mathbf{N}}{\text { Nhóm }}$ & $\begin{array}{c}\text { Nhóm } \\
\text { D }\end{array}$ & & $\begin{array}{c}\text { Nhóm } \\
\mathbf{N}\end{array}$ & $\begin{array}{c}\text { Nhóm } \\
\text { D }\end{array}$ & \\
\hline To & $\begin{array}{c}0.23 \pm \\
0,16\end{array}$ & $\begin{array}{c}0.26 \pm \\
0.14\end{array}$ & $p>0.05$ & $\begin{array}{l}0.3 \pm \\
0.19\end{array}$ & $\begin{array}{c}0.33 \pm \\
0.16\end{array}$ & $p>0.05$ & $\begin{array}{l}1.37 \pm \\
0.37\end{array}$ & $\begin{array}{c}1.45 \pm \\
0.29\end{array}$ & $p>0.05$ \\
\hline $\mathbf{T}_{1}$ & $\begin{array}{c}0.3 \pm \\
0.1 \\
\end{array}$ & $\begin{array}{c}0.33 \pm \\
0.16 \\
\end{array}$ & $p>0.05$ & $\begin{array}{c}0.36 \pm \\
0.25 \\
\end{array}$ & $\begin{array}{c}0.47 \pm \\
0.18 \\
\end{array}$ & $p>0.05$ & $\begin{array}{c}1.37 \pm \\
0.37 \\
\end{array}$ & $\begin{array}{c}1.45 \pm \\
0.29 \\
\end{array}$ & $p>0.05$ \\
\hline$T_{2}$ & $\begin{array}{c}0.33 \pm \\
0.22\end{array}$ & $\begin{array}{c}0.36 \pm \\
0.11 \\
\end{array}$ & $p>0.05$ & $\begin{array}{c}0.43 \pm \\
0.28\end{array}$ & $\begin{array}{c}0.5 \pm \\
0.24\end{array}$ & $p>0.05$ & $\begin{array}{c}1.37 \pm \\
0.37 \\
\end{array}$ & $\begin{array}{c}1.43 \pm \\
0.27\end{array}$ & $p>0.05$ \\
\hline
\end{tabular}

${ }^{(\mathrm{mw})}$ Kiếm định Mann-Whitney; ${ }^{(\mathrm{t})}$ Kiếm định $\mathrm{t}$ - test độc lập

Nhóm $\mathrm{D}$ có $\mathrm{PI}$ cao hơn nhóm $\mathrm{N}$ tại cả 3 thời điểm đánh giá, tuy nhiên sự khác biệt không có ý nghĩa thống kê $(p>0.05)$.

Ngoài ra, giá trị GI của nhóm D cũng cao hơn nhóm $\mathrm{N}$ tại cả 3 thời điểm, nhưng sự khác biệt không có ý nghĩa thống kê ( $p>0.05)$.

Giá trị PDkhông có sự khác biệt có ý nghĩa thống kê giữa 2 nhóm $D$ và $N$ ở cả 3 thời điểm ( $p$ $>0.05$ ).

\section{BÀN LUÂ̂N}

Vị trí đường hoàn tất mão toàn sứ. Có 3 vị trí ĐHT cho phục hình mão răng gồm: ĐHT trên nướu, ngang nướu và dưới nướu. Trong nghiên cứu này, chúng tôi thực hiện ĐHT mặt ngoài của răng nghiên cứu nằm ngang nướu hoặc dưới bờ nướu viền $0.5 \mathrm{~mm}$. Các răng được chọn vào nghiên cứu có độ sâu thăm dò của khe nướu từ 1$3 \mathrm{~mm}$ để đảm bảo không vi phạm khoảng sinh học khi sửa soạn ĐHT dưới nướu $0.5 \mathrm{~mm}$.

Chỉ số nha chu lâm sàng của nhóm $\mathbf{N}$ và nhóm răng chứng. ĐHT ngang nướu thuận lợi cho việc sửa soạn răng, thực hiện phục hình và giúp bệnh nhân dễ dàng kiểm soát mảng bám. Trong nghiên cứu này, các chỉ số PI, GI, PDcủa nhóm mão có ĐHT ngang nướuthay đối không có ý nghĩa thống kê giữa các thời điểm, ngoài ra cũng không có sự khác biệt giữa nhóm $\mathrm{N}$ với nhóm chứng $(p>0.05)$ (xem Bảng 2). Có thể thây PI có giá trị thấp hơn 1 ,có nghĩa là ở đa số răng, mảng bám ko thể nhận ra bằng mắt thường và bệnh nhân kiểm soát mảng bám tốt. Heboyan (2021) cho rằng zirconia có khả năng tương hợp sinh học cao với mô nha chu và có ít tác động ảnh hưởng đến viền nướu[1].

Chỉ số nha chu lâm sàng của nhóm $D$ và nhóm răng chứng. Kết quả nghiên cứu của chúng tôi cho thấy các chỉ số PI, GI và PD của nhóm mão có ĐHT dưới nướu khác biệt không có ý nghĩa thống kê so với nhóm chứng tại cả 3 thời điểm, ngoài ra các chỉ số này cũng không có sự khác biệt giữa các thời điểm đánh giá $(p>0.05)$ (xem Bảng 3).

Một nghiên cứumới gần đây của Serra-Pastor (2021) trên mão toàn sứ với ĐHT dưới nướu cho thấy chỉ số PI được cải thiện đáng kể, giảm có ý nghĩa thống kê sau 6 năm theo dõi, chỉ số GI và PD khác biệt không có ý nghĩa thống kê giữa các thời điểm đánh giá [6]. Tác giả cho rằng sự liên tục và khít sát tốt giữa mô răng và phục hình là yếu tố quan trọng giúp cải thiện tình trạng mô nha chu. Tuy nhiên, nghiên cứu của Paniz (2016) cho rằng các chỉ số $\mathrm{PI}, \mathrm{GI}$ và $\mathrm{BOP}$ tăng lên có ý nghĩa thống kê sau khi gắn mão toàn sứ với $\mathrm{DHT}$ dưới nướu 12 tháng [4]. Tác giả đã lý giải sự khác biệt có thể do vi phạm khoảng sinh học, thiếu chiều cao nướu sừng hóa hay hình dạng mão không thích hợp [5].

Bàn luận các chỉ số nha chu lâm sàng giữa nhóm $\mathbf{N}$ và nhóm $\mathbf{D}$. Trong nghiên cứu này, việc kiểm soát độ khít sát và chính xác của bờ mão với mô răng, vị trí ĐHT và hình dạng mão thích hợp, đồng thời hướng dẫn và khuyến khích $\mathrm{BN}$ sử dụng các biện pháp kiểm soát mảng bám và giữ vệ sinh răng miệng tốt đã góp phần khiến cho chỉ số PI, GI và PD giữa 2 nhóm mão có ĐHT ngang nướu và dưới nướu không khác biệt nhiêu và cũng không khác biệt so với nhóm chứng $(\mathrm{p}>0.05)$

Tương đồng với kết quả nghiên cứu này, Paniz (2020) thực hiện nghiên cứu cắt ngang mô tả trên mão toàn sứ với ĐHT dưới nướu $0.5 \mathrm{~mm}$ có thời gian tồn tại trung bình là 5 năm đã báo cáo rằng $Đ H T$ dưới nướu có thể duy trì mô nha chu lành mạnh và ổn định nếu quy trình phục hình được kiểm soát và BN giữ VSRM tốt [5]. 
Tuy nhiên, Nayer và cs. (2012) báo cáo rằng nhóm mão toàn sứ với ĐHT dưới nướu có chỉ số PI, GI và PD cao hơn có ý nghĩa thống kê so với nhóm ĐHT trên nướu, khác với kết quả của nghiên cứu hiện tại [8]. Kết quả khác biệt này có thể do ĐHT dưới nướu khó lấy dấu chính xác để làm được mão khít sát với mô răng, khó kiểm soát dẫn đến dư, hở bờ mão với mô răng,hình dạng mão sai, gây tăng tích tụ mảng bảm ngay dưới bờ $\mathrm{PH}$, hoặc do sự vi phạm khoảng sinh học đã gây tổn thương mồ nha chu.

\section{KẾT LUÂN}

Qua nghiên cứu trên cho thấy không có sự khác biệt về ảnh hưởng của các vị trí đường hoàn tất lên chỉ số lâm sàng của mô nha chu quanh răng khi thực hiện phục hình mão răng toàn sứ trên răng trước đã nội nha trong ngày thứ 1, 45 ngày và 90 ngày sau khi gắn phục hình. Cần thực hiện đúng quy trình phục hình, lựa chọn vị trí đường hoàn tất thích hợp và hướng dẫn vệ sinh răng thích hợp để đảm bảo sự lành mạnh của mô nha chu cũng như thành cổng lâu dài của phục hình mão toàn sứ.

\section{TÀI LIẸU THAM KHẢO}

1. Heboyan A., Manrikyan M., et al. "Bacteriological evaluation of gingival crevicular fluid in teeth restored using fixed dental prostheses: An in vivo study". Int J Mol Sci, 2021, 22(11):5463.

2. Loe H., Silness J. "Periodontal disease in pregnancy. I. Prevalence and severity". Acta Odontol Scand, 1963, 21:533-51.

3. Orkin D. A., Reddy J., et al. "The relationship of the position of crown margins to gingival health". J Prosthet Dent, 1987, 57(4):421-424.

4. Paniz G., Nart J., et al. "Periodontal response to two different subgingival restorative margin designs: a 12-month randomized clinical trial". Clin Oral Investig, 2016, 20(6):1243-52.

5. Paniz G., Zarow M., et al. "Dual-center crosssectional analysis of periodontal stability around anterior all-ceramic crowns with a feather-edge or chamfer subgingival preparation". Int J Periodontics Restorative Dent, 2020, 40(4):499-507.

6. Serra-Pastor B., Bustamante-Hernández $\mathbf{N}$., et al. "Periodontal behavior and patient satisfaction of anterior teeth restored with single zirconia crowns using a biologically oriented preparation technique: A 6-year prospective clinical study". J Clin Med, 2021, 10(16):3482.

7. Silness J., Loe H. "Periodontal disease in pregnancy. II. Correlation between oral hygiene and periodontal condtion". Acta Odontol Scand, 1964, 22:121-35.

8. Nayer A., Rayyan M. M., et al. "An update on the effect of crown margin locations and materials on periodontal health". Egyptian dental journal, 2012, 58(3639):3644.

\section{ĐộNG LỰC LÀM VIỆC CỦA ĐIỀU DƯỡNG LÂM SÀNG VÀ MộT Số YẾU Tố ẢNH HƯỞNG TẠI BỆNH VIÊ̂N ĐA KHOA TÂY NINH NĂMM 2019}

\section{TÓM TẮT}

Mục tiêu: Khảo sátđộng lực làm việc (ĐLLV)và môt số yếu tố ảnh hưởng của điều dưỡng lâm sàng (ĐDLS) tại Bệnh viện Đa khoa Tây Ninh năm 2019.Đối tương và phương pháp: Các ĐDLS đang làm viêc tai Bệnh viện Đa khoa Tây Ninh.: Thiết kế cắt ngang mô tả với bộ câu hỏi định lượng tại Bệnh viện (BV)trong thời gian tháng 04 - 10/2019. Bộ câu hỏi sử dụng thang đo đánh giá ĐLLV được Mbindyo và cộng sự (2009) đã được chuẩn hóa,được tính điểm theo thang điểm Likert 5 điểm, từ "Rất không đồng ý-(1)" đến "Rất đồng ý-(5)". Phân tích và xử lý số liệu bằng SPSS 20. Kết quả: Kết quả ghi nhận có 269 ĐDLS tham gia

\footnotetext{
${ }^{1}$ Bệnh viện Đa Khoa Tây Ninh

${ }^{2}$ Trường $Đ H$ Y tế Công cộng Hà Nội.

${ }^{3}$ Trướng $Đ H$ Y khoa Phạm Ngoc Thach.

Chịu trách nhiệm chính: Võ Quang Trung

Email: trungvq@pnt.edu.vn

Ngày nhân bài: 27/8/2021

Ngày phản biên khoa hoc: 20/9/2021

Ngày duyệt bài: 17/10/2021
}

vớiđiểm ĐLLV trung bình chung đat $3,14 \pm 0,32$ điểm (trên thang đo 5 điểm). Yếu tố "sức khỏe" và "sư tận tâm" là 2 yếu tố có điểm trung bình cao nhất $(3,45$ và 3,42 điểm), ngược lại yếu tố "tuân thủ giờ giấc và sự tham gia" có điểm trung bình thấp nhất với 2,79 điểm. Nghiên cứu cho thây các đặc điểm về giới tính, trình đồ học vấn, tình trang hôn nhân, mức thu nhâp, thâm niên làm việc và loại hợp đồng làm việc có ảnh hưởng đến ĐLLV. Kết luâan:Đông lức làm viêc của ĐDLS tai BV Đa Khoa Tây Ninh đạt mức trung bìnhvà nhiều đặc điểm của điều dưỡng lâm sàng có ảnh hưởng đếnĐLLV. "Sức khỏe" và "sự tận tâm" là yếu tố động lực ĐDLS đánh giá cao nhất, trong khi "sự tuân thủ và tham gia" có điểm ĐLLV thấp nhất.

Tứ khóa: Bệnh viện, điều dưỡng, động lực, Tây Ninh.

\section{SUMMARY}

WORK MOTIVATION OF CLINICAL NURSING AND ASSOCIATED FACTORS AT TAY NINH GENERAL HOSPITAL IN 2019

Objectives: Assessing motivation to work and associated factors at Tay Ninh General Hospital. 